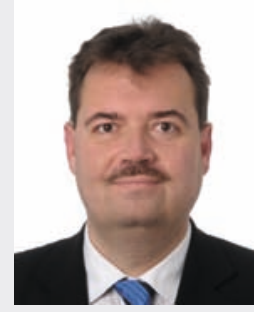

Prof. Dr. Dr. Oliver Ullrich

\section{Eine Frage des Horizontes}

Liebe Kolleginnen und Kollegen,

der Horizont der Menschheit reicht heute so weit wie nie jemals zuvor. Dank des Hubble-Weltraumteleskops wurden bislang mehr als 2000 Exoplaneten gefunden, die ersten nach dem Urknall entstandenen Galaxien untersucht, die Existenz Schwarzer Löcher belegt und die erste 3D-Karte der dunklen Materie erstellt. Unser Horizont reicht heute bis in die entferntesten Ecken des Universums.

Bei manchen Menschen reicht der Horizont aber leider nicht für Lichtjahre, sondern nur für wenige Kilometer. Daher hat die bemannte Raumfahrt und die Forschung im Weltraum einen schweren Stand. Jedes Mal, wenn irgendwo über eine neue Weltraummission berichtet wird, ruft mit Sicherheit jemand: Zu teuer, zu geringer Nutzen, und das ganze Geld sei viel besser in der Krebsforschung oder in die Bekämpfung der Armut investiert. Nur dass durch den Verzicht auf Raumfahrt weder Krebs noch Armut beseitigt werden kann, sollte selbst dem naivsten Gemüt klar sein. Verzicht auf Forschung und Fortschritt dagegen hat noch niemals die Menschheit irgendwo weitergebracht. Aber Forschung im Weltraum muss sich heute konstant rechtfertigen. Vor allem mit einem „Benefit für die Erde“. Damit ist aber keineswegs der Benefit für den Menschen als forschende und entdeckende Spezies gemeint, gemeint sind kurzfristige und sichtbare Anwendungsnutzen, also Dinge, die gerade noch in den eingeschränkten Horizont derjenigen hineinpassen, die solche Fragen stellen.

Es gibt nachvollziehbare Gründe, bemannte interplanetare Raumfahrt abzulehnen, denn immerhin hat unser Planet Erde noch ein sattes Drittel seiner Lebensspanne vor sich und es wird noch gut eine Milliarde Jahre dauern, bis die zum „Roten Riesen“ gewordene Sonne jedes menschliche Leben auf der Erde auslöschen wird. Das ist viel Zeit. Aber eines Tages muss sich der Mensch entscheiden. Bleibt er auf seinem Planeten hocken und wartet auf das ferne, aber absolut sichere Ende seiner Existenz oder bleibt er die mobile, entdeckende, anpassungsfähige Spezies, die er immer war, seitdem er vor gut 100000 Jahren „out of Africa“ jeden Winkel der Erde erfolgreich besiedelte?

In der Höhle zu bleiben, war keine taugliche Überlebensstrategie. Und das Weltall draußen einfach zu ignorieren, ist es mit Sicherheit auch nicht. Als interplanetar mobile Spezies müsste der Mensch bis zu den nächsten erdähnlichen Planeten mehr als 20 Lichtjahre zurücklegen. Reisen über Distanzen von Lichtjahren? Ein Ding der Unmöglichkeit? Aus heutiger Sicht bestimmt ja. Genauso wie der berühmte Physiker und Präsident der Royal Society Lord Kelvin im Jahr 1895 unmissverständlich klarstellte: Flugmaschinen, die schwerer als Luft sind, sind ein Ding der Unmöglichkeit.

Aber weniger als 10 Jahre später erhoben sich diese „unmöglichen“ Flugmaschinen regelmäßig in die Luft, und 74 Jahre später landeten Menschen auf dem Mond. 